\title{
Efficacy of microwave ablation versus radiofrequency ablation for hepatocellular carcinoma: a propensity score analysis
}

\author{
Kanehiko Suwa ${ }^{1,2}$ D $\cdot$ Toshihito Seki $^{2} \cdot$ Kazunori Aoi $^{1,2} \cdot$ Masao Yamashina $^{1,2} \cdot$ Miki Murata $^{1,2} \cdot$ Noriyo Yamashiki $^{1}$. \\ Akiyoshi Nishio $^{1} \cdot$ Masaaki Shimatani $^{1} \cdot$ Makoto Naganuma $^{1}$
}

Received: 30 December 2020 / Revised: 14 February 2021 / Accepted: 20 February 2021 / Published online: 6 March 2021

(c) The Author(s) 2021

\begin{abstract}
Purpose To evaluate the efficacy and safety of radiofrequency ablation (RFA) and new-generation microwave ablation (MWA) for the treatment of hepatocellular carcinoma (HCC).

Methods The propensity score matching method was applied to patients with HCC treated with MWA (93 patients) or RFA (156 patients) at a single institution from January 2014 to April 2020. The local tumor progression (LTP), intrahepatic distant recurrence (IDR), and recurrence-free survival (RFS) of the two matched therapies were analyzed using the Kaplan-Meier method. Cox proportional hazard models were used to identify risk factors for LTP and RFS. The therapeutic effects and complications of the two treatments were also compared.

Results The LTP, IDR, and RFS of MWA and RFA were equivalent (LTP: hazard ratio [HR] $=0.87$; 95\% confidence interval [95\% CI] 0.36- 2.07; $P=0.746$, IDR: HR $=1.03 ; 95 \%$ CI $0.61-1.73 ; P=0.890$, RFS: HR $=1.15 ; 95 \%$ CI $0.69-$ 1.91; $P=0.566)$. Para-vessel lesions was the only risk factor for LTP, whereas age, previous treatment, Albumin-Bilirubin score, and tumor diameter were risk factors for RFS. On the other hand, the ablation time per nodule $(6.79 \pm 2.73$ and $9.21 \pm 4.90 \mathrm{~min} ; P=0.008)$ and number of sessions per nodule required to achieve technical success $(1.16 \pm 0.39$ and $1.34 \pm 0.57 ; P=0.009)$ were significantly lower in MWA than in RFA. The major complication rate of MWA and RFA was also equivalent.

Conclusion MWA and RFA have similar therapeutic effects and safety, although MWA has advantages over RFA regarding efficacy, including shorter ablation time and fewer sessions required.
\end{abstract}

Keywords Hepatocellular carcinoma - Microwave ablation · Radiofrequency ablation · Local tumor progression · Recurrence-free survival

\author{
Kanehiko Suwa \\ suwakan@takii.kmu.ac.jp \\ Toshihito Seki \\ sekit@takii.kmu.ac.jp \\ Kazunori Aoi \\ aoikaz@takii.kmu.ac.jp \\ Masao Yamashina \\ yamashim@takii.kmu.ac.jp \\ Miki Murata \\ muratami@takii.kmu.ac.jp \\ Noriyo Yamashiki \\ yamashno@takii.kmu.ac.jp \\ Akiyoshi Nishio \\ nishioa@takii.kmu.ac.jp
}

\author{
Masaaki Shimatani \\ shimatam@hirakata.kmu.ac.jp \\ Makoto Naganuma \\ naganuma@hirakata.kmu.ac.jp \\ 1 The Third Department of Internal Medicine, Division \\ of Gastroenterology and Hepatology, Kansai Medical \\ University, 2-3-1 Shimmachi, Hirakata, Osaka 573-1101, \\ Japan \\ 2 Kansai Medical University Medical Center, Liver Disease \\ Center, 10-15 Fumizonocho, Moriguchi, Osaka 570-8507, \\ Japan
}




\section{Introduction}

Hepatocellular carcinoma (HCC) is one of the leading causes of cancer-related death globally, and it is estimated that both its incidence and mortality are increasing worldwide [1]. The Barcelona Clinic Liver Cancer staging classification and treatment schedule, one of the most widely adopted liver cancer staging systems, recommends liver transplantation, resection, and ablation therapy as curative treatments for early-stage $\mathrm{HCC}[2,3]$. Thermal ablation procedures are the best option as a curative treatment for patients with HCC who cannot undergo surgical resection or liver transplantation due to their high local tumor control and minimally invasive nature [4]. Several metaanalyses suggest that thermal ablation may be favorable as a first-line treatment $[5,6]$. Radiofrequency ablation (RFA) is widely used in thermal ablation, and most largescale HCC trials have been performed using RFA [7-9]. More recently, the Emprint Ablation System ${ }^{\mathrm{TM}}$ (Covidien), a microwave ablation (MWA) system with new technology, has gained increased attention $[10,11]$. This new system opens up an interesting perspective as to the optimal selection of ablation modalities for local therapy for HCC. This study adopted a propensity score matching (PSM) analysis to reduce potential confounding bias at baseline. The purpose of this study was to investigate the therapeutic efficacy and safety of MWA versus RFA systems and to analyze the predictors that might influence the superiority of one system over the other.

\section{Materials and methods}

\section{Patients}

This retrospective study evaluated patients treated with percutaneous thermal ablation (PTA) at the Kansai Medical University Medical Center, Liver Disease Center between January 2014 and April 2020. RFA was utilized for all patients treated before November 2017, whereas MWA was routinely used after November 2017. Exceptionally, during 2018, RF was used in three cases due to generator problems. The study group included 93 patients treated with MWA and 156 patients treated with RFA. Patients receiving palliative therapy or those with extrahepatic metastases or portal vein tumor thrombosis were excluded to assess treatment efficacy correctly. We also excluded patients with a tendency toward severe bleeding, and those whose liver function was Child-Pugh Class $\mathrm{C}$ with refractory ascites. All patients were treated with a curative intent and the tumors were within the Milan criteria.
The study protocol was conducted with the approval (approval no. 2018143) of the Ethics Committee of Kansai Medical University Medical Center (Moriguchi, Japan). All study procedures were performed in accordance with the ethical standards of the Clinical Research Board of Kansai Medical University Medical Center and with the 1964 Helsinki Declaration and its later amendments or comparable ethical standards. Informed consent was obtained from all participants included in the study.

\section{Diagnosis}

Clinical diagnosis and cancer grading were performed using computed tomography (CT) during angiography (CT-A) and computed tomography during arterial portography (CT-AP). If a clinical diagnosis was difficult, the histological diagnosis of tumors was confirmed by ultrasound (US) guided fine needle biopsy.

Large vessels were defined as having a diameter greater than $3 \mathrm{~mm}$, and $\mathrm{HCC}$ adjacent to large vessels was defined as a lesion confirmed to be in contact with large vessels on the US screen.

\section{Ablation procedure}

Both operators who performed PTA procedures had more than 5 years of experience in intervention therapy at the start of this study and treated patients in the same manner. All ablation procedures were performed via a percutaneous approach under US guidance (TUS-A300 Aplio300; Canon). After local anesthesia was administered as $0.5 \%$ lidocaine hydrochloride (Aspen Japan), a guide needle (MWA, 12 G $\times 140$ mm; RFA, 14 G×145 mm; Hakko Medical) was inserted into the vicinity of the tumor under US guidance. Subsequently, the inner needle of the guide was removed, and the antenna (electrode) was inserted through the outer needle of the guide to place the antenna (electrode) in the tumor area.

Microwave ablation was performed using an Emprint ${ }^{\mathrm{TM}}$ Ablation Generator with Thermosphere Technology with an Emprint ${ }^{\mathrm{TM}}$ Long Percutaneous Antenna $(30 \mathrm{~cm}$; Covidien). Radiofrequency ablation was performed using a Cool-tip RF Generator with a Cool-tip RF single needle $(25 \times 3 \mathrm{~cm}$; Covidien). The output energy was optimized and adjusted appropriately according to each case. The output energy was set at $60-100 \mathrm{~W}$ and $80-120 \mathrm{~W}$ in the case of MWA and RFA, respectively. The ablation area was monitored by a real-time US, and ablations were terminated when the hyperechoic zone adequately covered the lesion on the US screen referring to the recommended time protocol for each device. If the ablation area was determined to be insufficient by the following evaluation method, additional ablation was performed at a later date. 


\section{Evaluation of treatment effect and follow-up}

Four days after ablation, the direct effect of ablation was determined by dynamic CT. Technical success was determined at each nodule and defined as a wide coagulated area around the circumference than the low-density area in the late phase of pretreatment dynamic CT. The initial technical success rate was determined after the initial ablation session, and the secondary technical success rate was determined as the proportion of successful treatment with repeated ablation.

All patients were closely followed after discharge from the hospital, and dynamic CT was performed every 3-4 months. When imaging studies revealed intrahepatic recurrence, the diagnosis was confirmed by $\mathrm{CT}$ angiography and/ or US-guided tumor biopsy. Local tumor progression (LTP) was defined as a recurrence of the nodule in the treatment area or the treatment area's margin. Complications were classified according to the Society of Interventional Radiology classification of complications by outcome [12]. The follow-up period ended in June 2020.

\section{Statistical analyses}

In this study, PSM analysis was applied only to the cases that had technical success to focus on tumor recurrences of the two ablation systems. Propensity scores were estimated using a logistic regression model, and 1:1 patient matching was performed based on each patient's propensity score. The variables included in the propensity score model were age, sex, background liver disease, platelet count, AlbuminBilirubin (ALBI) score [13], $\alpha$-fetoprotein (AFP), naïve or recurrence, tumor size, tumor number, adjacency to large vessels, and presence or absence of combination therapy with Conventional transcatheter arterial chemoembolization (c-TACE).

Group (MWA versus RFA) differences in clinical data were compared using Mann-Whitney U tests for continuous variables and Pearson's Chi-square tests for categorical variables. Cumulative incidence rates for LTP, intrahepatic distant recurrence (IDR), and recurrence-free survival (RFS) were estimated using the Kaplan-Meier method, and differences between groups were compared by the log-rank test. Risk factors for LTP and RFS were assessed using Cox proportional hazard models in univariate and multivariate analyses for all patients, not just the propensity scorematched patients. Each variable in the multivariate analysis was adjusted for items that were expected to be relevant to each event. All variables with $P$-values less than 0.10 in the univariate analysis were selected for the multivariate analysis. $P$-values less than 0.05 were considered to indicate a statistically significant difference. All statistical analyses were performed using the $\mathrm{R}$ statistical package (R software version 3.4.1; R Foundation for Statistical Computing, Vienna, Austria).

\section{Results}

\section{Patient population}

The full study cohort comprised 249 patients, including 93 patients treated with MWA and 156 patients treated with RFA. The follow-up period was longer in patients treated with RFA, as RFA was routinely used at the study's inception (median follow-up of 364 vs. 1150 days). Baseline characteristics of all patients are shown in Table 1. c-TACE using iodized oil emulsion (4-6 ml, Lipiodol, Andre Guerbet) was performed for all tumors when diagnosed as HCC with CT-A and CT-AP. Before PSM, the RFA group had significantly less para-vessel lesions than the MWA group (44.1\% vs. $19.2 \%)$ but were associated with worse underlying liver disease such as lower prothrombin time, and albumin and platelet counts ( 86.8 vs. $77.3 \%, 3.9$ vs. $3.7 \mathrm{~g} / \mathrm{dl}$, 14.2 vs. $11.8 \times 104 / \mu \mathrm{l}$, respectively). One hundred forty-four patients were selected during PSM, and after matching, the two groups were not significantly different in terms of baseline factors (Table 1).

\section{Treatment efficacy}

Eighty-eight of the 93 patients in the MWA group and 140 of the 156 patients in the RFA group achieved initial technical success ( 94.6 vs. $89.7 \%$ ), 92 patients in the MWA group and 151 patients in the RFA group achieved secondary technical success (98.9 vs. $96.7 \%$ ). There was no group difference in technical success rates. In the two matched groups, the average number of sessions per nodule required to achieve technical success was significantly fewer for MWA $(1.16 \pm 0.39)$ than for RFA $(1.34 \pm 0.57)(P=0.009)$. Similarly, the average ablation time per nodule was significantly shorter for MWA $(6.79 \pm 2.73 \mathrm{~min})$ than for RFA $(9.21 \pm 4.90 \mathrm{~min})$ $(P=0.008)$. Treated nodules whose coagulated area included $5 \mathrm{~mm}$ or more safety margin from the tumor were 59 out of 86 nodules for MWA and 48 out of 86 nodules for RFA, and there was no significant difference between the two groups $(P=0.115)$.

\section{Tumor recurrence}

Cumulative LTP rates for 1 and 2 years were $10.9 \%$ and $24.4 \%$ for MWA, and $8.3 \%$ and $19.9 \%$ for RFA, respectively (hazard ratio $[\mathrm{HR}]=0.87 ; 95 \%$ confidence interval $[95 \% \mathrm{CI}]$ 0.36 to $2.07 ; P=0.746$ ) (Fig. 1a). Cumulative IDR rates for 1 and 2 years were $26.2 \%$ and $65.5 \%$ for MWA and $32.4 \%$ and $53.5 \%$ for RFA, respectively $(\mathrm{HR}=1.03$; $95 \%$ CI 0.61 
Table 1 Baseline characteristics before and after propensity score

\begin{tabular}{|c|c|c|c|c|c|c|}
\hline \multirow[b]{2}{*}{ Variables } & \multicolumn{3}{|c|}{ Before propensity score matching } & \multicolumn{3}{|c|}{ After propensity score matching } \\
\hline & MWA & RFA & $\mathrm{P}$-value & MWA & RFA & P-value \\
\hline Patient (n) & 93 & 156 & & 72 & 72 & \\
\hline Nodule (n) & 112 & 185 & & 86 & 86 & \\
\hline Observation period (days, median) & 364 & 1150 & & 330 & 1064 & \\
\hline Sex & & & 0.39 & & & 0.86 \\
\hline Male & 62 & 113 & & 47 & 49 & \\
\hline Female & 31 & 43 & & 25 & 23 & \\
\hline Age (y) & $74.17 \pm 8.35$ & $72.38 \pm 9.51$ & 0.133 & $74.90 \pm 8.43$ & $74.40 \pm 9.19$ & 0.734 \\
\hline Background & & & 0.814 & & & 0.931 \\
\hline HBV & 10 & 21 & & 6 & 6 & \\
\hline $\mathrm{HCV}$ & 56 & 93 & & 47 & 44 & \\
\hline NBNC & 27 & 42 & & 19 & 22 & \\
\hline Type -naïve or recurrent & & & 0.672 & & & 0.858 \\
\hline Naive & 27 & 50 & & 22 & 24 & \\
\hline Recurrent & 66 & 106 & & 50 & 48 & \\
\hline Child-Pugh class & & & 0.627 & & & 0.661 \\
\hline A & 76 & 123 & & 58 & 61 & \\
\hline B & 17 & 33 & & 14 & 11 & \\
\hline PT $(\%)$ & $86.86 \pm 17.12$ & $77.38 \pm 13.46$ & $<0.001$ & $86.56 \pm 15.99$ & $79.56 \pm 14.52$ & 0.007 \\
\hline $\operatorname{ALB}(\mathrm{g} / \mathrm{dl})$ & $3.96 \pm 0.58$ & $3.77 \pm 0.56$ & 0.011 & $3.90 \pm 0.59$ & $3.93 \pm 0.54$ & 0.79 \\
\hline T-Bil (mg/dl) & $0.95 \pm 0.53$ & $1.02 \pm 1.00$ & 0.538 & $1.02 \pm 0.52$ & $0.95 \pm 0.52$ & 0.395 \\
\hline $\operatorname{PLT}\left(10^{4} / \mu \mathrm{l}\right)$ & $14.25 \pm 6.16$ & $11.85 \pm 7.30$ & 0.008 & $13.64 \pm 6.03$ & $12.63 \pm 6.77$ & 0.348 \\
\hline ALBI score & $-2.60 \pm 0.54$ & $-2.43 \pm 0.51$ & 0.01 & $-2.53 \pm 0.54$ & $-2.57 \pm 0.50$ & 0.628 \\
\hline $\operatorname{AFP}(\mathrm{ng} / \mathrm{ml})$ & $111.79 \pm 613.22$ & $119.29 \pm 477.25$ & 0.914 & $47.24 \pm 152.64$ & $32.28 \pm 87.54$ & 0.472 \\
\hline TACE & & & 0.1 & & & 0.845 \\
\hline Yes & 75 & 111 & & 56 & 54 & \\
\hline No & 18 & 45 & & 16 & 18 & \\
\hline Location & & & $<0.001$ & & & 0.862 \\
\hline Vessel-adjacent & 41 & 30 & & 25 & 27 & \\
\hline Non vessel-adjacent & 52 & 126 & & 47 & 45 & \\
\hline Tumor size (mm) & $18.47 \pm 8.29$ & $17.52 \pm 6.60$ & 0.322 & $17.72 \pm 6.76$ & $17.55 \pm 6.29$ & 0.874 \\
\hline Tumor number & $1.85 \pm 1.18$ & $1.77 \pm 1.17$ & 0.603 & $1.88 \pm 1.17$ & $1.88 \pm 1.20$ & 1 \\
\hline
\end{tabular}

$M W A$ Microwave ablation, $R F A$ radiofrequency ablation, $H B V$ hepatitis $\mathrm{B}$ virus, $H C V$ hepatitis $\mathrm{C}$ virus, $N B N C$ non $\mathrm{B}$ non-C, $P T$ prothrombin time, $A L B$ albumin, $T$-Bil total bilirubin, $P L T$ platelet, $A L B I$ albumin bilirubin grade, AFP $\alpha$ fetoprotein, TACE transcatheter arterial chemoembolization

to $1.73 ; P=0.890$ ) (Fig. 1b). Cumulative RFS rates for 1 and 2 years were $71.4 \%$ and $35.3 \%$ for MWA and $66.1 \%$ and $40.4 \%$ for RFA, respectively (HR $=1.15 ; 95 \%$ CI 0.69 to $1.91 ; P=0.566$ ) (Fig. 1c). Multivariate analysis, adjusted for propensity scores, showed no significant difference between MWA and RFA in terms of tumor recurrence.

\section{Complications}

One patient each in the MWA and RFA groups had subcapsular hemorrhage after ablation. One liver infarction and one pneumothorax occurred in the MWA group, whereas one cholecystitis and one liver abscess occurred in the RFA group. The complication rate was the same in both groups (4.16\% vs. $4.16 \%)$. No treatment-related deaths occurred. None of the patients developed local dissemination of the cancer cells along the puncture line.

\section{Risk factors associated with LTP and RFS}

We further investigated the risk factors for LTP and RFS after PTA. The risk of LTP adjacent to large vessels $(\mathrm{HR}=3.013 ; 95 \%$ CI 1.46 to $6.186 ; P=0.002)$ was the only risk factor associated with PTA (Table 2). In contrast, age, viral hepatitis, recurrent type, ALBI score, AFP, tumor diameter, tumor number, and RFA were identified as risks 

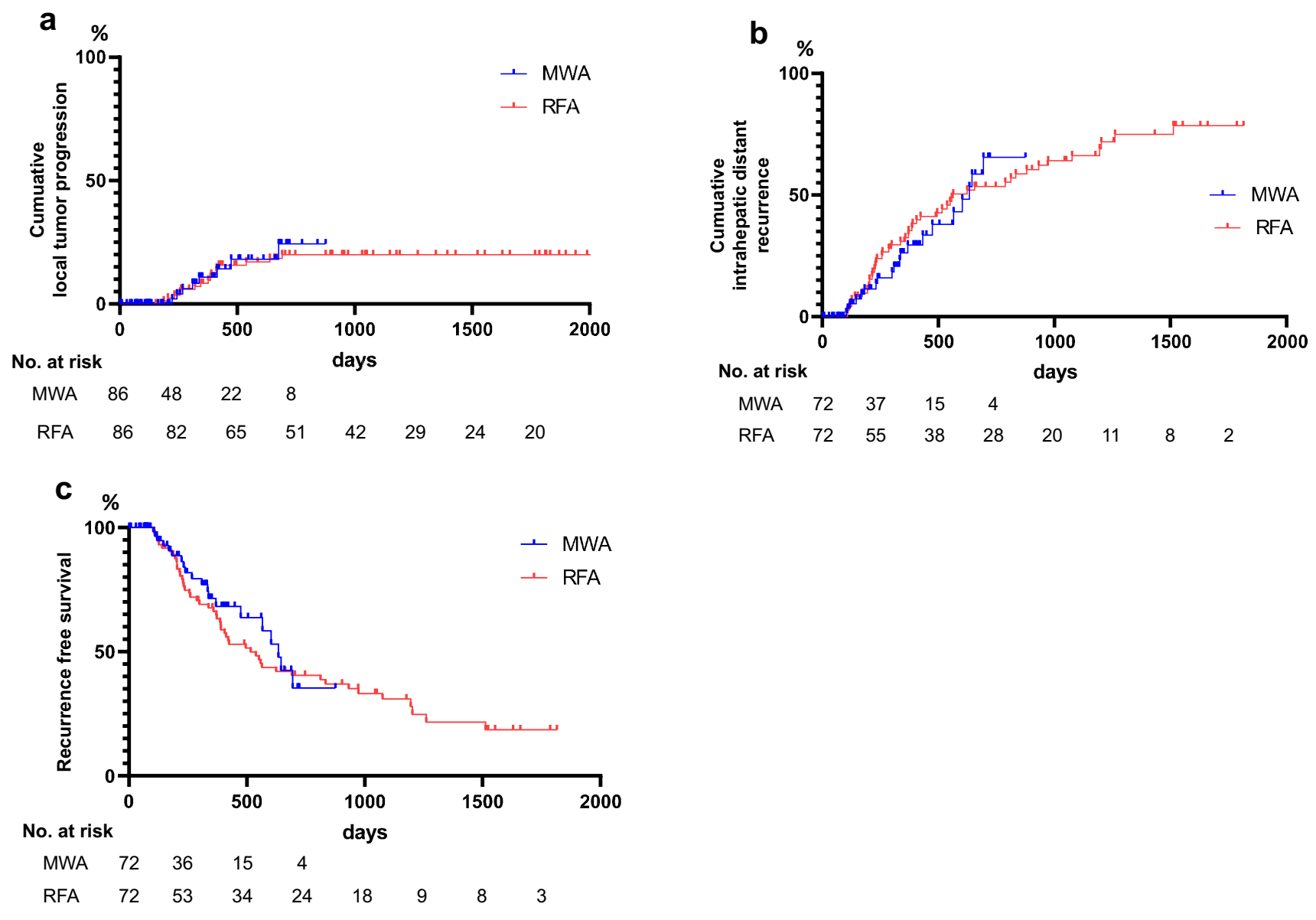

Fig. 1 Kaplan-Meier curves of hepatocellular carcinoma patients with microwave ablation (MWA) or radiofrequency ablation (RFA). a local tumor progression after matching; $\mathbf{b}$ intrahepatic distant recurrence after matching; $\mathbf{c}$ recurrence-free survival after matching

Table 2 Univariate analyses of predictive factors for local tumor progression

\begin{tabular}{lll}
\hline Variables & Hazard Ratio $(95 \% \mathrm{CI})$ & P Value \\
\hline Background (viral hepatitis) & $1.558(0.641-3.784)$ & 0.328 \\
ALBI $(-2.60)$ & $0.801(0.396-1.622)$ & 0.539 \\
PLT $\left(>10 \times 10^{4}\right)$ & $0.902(0.45-1.808)$ & 0.771 \\
AFP $(>20 \mathrm{ng} / \mathrm{ml})$ & $0.953(0.441-2.061)$ & 0.904 \\
Tumor size $(>3 \mathrm{~cm})$ & $1.133(0.154-8.314)$ & 0.903 \\
TACE $(+)$ & $0.905(0.418-1.957)$ & 0.800 \\
Location (vessel-adjacent) & $1.866(1.328-2.621)$ & 0.000 \\
Device (RFA) & $0.694(0.317-1.52)$ & 0.362 \\
Ablation time & $1.018(0.950-1.09)$ & 0.613 \\
Session & $1.076(0.600-1.928)$ & 0.806 \\
\hline
\end{tabular}

$R F A$ radiofrequency ablation, $P L T$ platelet, $A L B I$ albumin bilirubin grade, $A F P \propto$ fetoprotein, $T A C E$ transcatheter arterial chemoembolization

associated with RFS in univariate analyses. In the multivariate analysis age $(\mathrm{HR}=1.873 ; 95 \% \mathrm{CI} 1.085$ to 3.232 ; $P=0.024)$ recurrent type $(\mathrm{HR}=3.329 ; 95 \% \mathrm{CI} 2.047$ to
5.412; $P<0.001)$, ALBI score (HR $=1.633 ; 95 \%$ CI 1.101 to $2.422 ; P=0.014)$, and tumor diameter $(\mathrm{HR}=2.626 ; 95 \%$ CI 1.175 to $5.867 ; P=0.018$ ) were identified as independent risks associated with RFS (Table 3 ).

\section{Discussion}

With the widespread use of surveillance programs for HCC in high-risk patients, patients are increasingly indicated for curative treatment [14]. Heat-based thermal ablations are the best therapies for patients with early-stage HCC who are unsuitable for surgery, although the difference in treatment efficacy between MWA and RFA is unclear, and the choice of therapy is often at the discretion of each institution and operator. Furthermore, with the advent of new MWA systems that eliminate the shortcomings of first-generation systems, the comparison between MWA and RFA is still a meaningful topic. This study applied PSM to reduce the confounding bias of patients' baseline characteristics when comparing the two therapies. PSM helped illustrate the value 
Table 3 Univariate and multivariate analyses of risk factors for cumulative recurrence-free survival

\begin{tabular}{|c|c|c|c|c|}
\hline Variables & Hazard ratio $(95 \% \mathrm{CI})$ & $P$ value & Hazard ratio $(95 \% \mathrm{CI})$ & $P$ value \\
\hline Age $(>65)$ & $1.728(1.015-2.942)$ & 0.044 & $1.873(1.085-3.232)$ & 0.024 \\
\hline Sex (male) & $0.981(0.662-1.454)$ & 0.926 & & \\
\hline Background (viral hepatitis) & $1.559(0.988-2.459)$ & 0.056 & $1.180(0.719-1.935)$ & 0.511 \\
\hline Naïve (recurrent type) & $3.413(2.121-5.492)$ & 0.000 & $3.329(2.047-5.412)$ & 0.000 \\
\hline Child-Pugh (B) & $1.09(0.696-1.706)$ & 0.708 & & \\
\hline $\operatorname{ALBI}(>-2.60)$ & $1.553(1.069-2.257)$ & 0.021 & $1.633(1.101-2.422)$ & 0.015 \\
\hline $\mathrm{PT}(>70 \%)$ & $0.950(0.627-1.441)$ & 0.811 & & \\
\hline $\operatorname{ALB}(>3.5 \mathrm{~g} / \mathrm{dl})$ & $0.813(0.539-1.227)$ & 0.326 & & \\
\hline T-Bil $(>2.0 \mathrm{mg} / \mathrm{dl})$ & $0.968(0.393-2.382)$ & 0.944 & & \\
\hline ALT $(>30 \mathrm{U} / \mathrm{L})$ & $0.918(0.640-1.316)$ & 0.641 & & \\
\hline $\operatorname{PLT}\left(>10 \times 10^{4}\right)$ & $0.976(0.945-1.01)$ & 0.164 & & \\
\hline $\operatorname{AFP}(>20 \mathrm{ng} / \mathrm{ml})$ & $1.442(0.983-2.116)$ & 0.061 & & \\
\hline Tumor size $(>3 \mathrm{~cm})$ & $3.818(1.734-8.41)$ & 0.001 & $2.626(1.175-5.867)$ & 0.019 \\
\hline Tumor number & $1.149(0.999-1.321)$ & 0.051 & $1.130(0.977-1.308)$ & 0.100 \\
\hline TACE $(+)$ & $0.951(0.628-1.44)$ & 0.814 & & \\
\hline Location (vessel-adjacent) & $1.001(0.657-1.522)$ & 0.998 & & \\
\hline Device (RFA) & $1.56(0.963-2.525)$ & 0.070 & $1.590(0.956-2.644)$ & 0.074 \\
\hline
\end{tabular}

RFA radiofrequency ablation, $P T$ prothrombin time, $A L B$ albumin, $T$-Bil total bilirubin, $A L T$ alanine aminotransferase, $P L T$ platelet, $A L B I$ albumin bilirubin grade, $A F P \propto$ fetoprotein, $T A C E$ transcatheter arterial chemoembolization of PTA as a treatment for HCC adjacent to large vessels, a major risk factor for local tumor progression. If the target lesion is in the vicinity of a large vessel, PTA cannot sufficiently cauterize the tissue due to the heat sink effect; a phenomenon that occurs when thermal energy diffuses away from the target lesion due to blood flow in adjacent vessels [15]. While the heat sink effect weakens RFA, the faster heating and higher temperature provided by microwave energy allow for a reduced heat sink effect $[16,17]$. Huang et al. reported the outcomes of MWA for HCC adjacent to large vessels and found that the risk did not significantly affect LTP and overall survival [18]. Similarly, Potretzke et al. reported that MWA had a lower rate of LTP than RFA [19], and Abdelaziz et al. reported that LTP was significantly lower in MWA than RFA, although overall survival was comparable [20]. On the other hand, Vogl et al. showed no significant differences between the two therapies in terms of complete treatment response, residual foci of untreated disease rate, recurrence rate, or progression-free survival [21].

In this study, before PSM, patients in the RFA group had a worse liver functional reserve, and the proportion of tumors adjacent to large vessels was lower than patients in the MWA group. Therefore, we applied PSM to reduce the confounding bias of these baseline characteristics between the two therapies. After PSM, patients with HCC in both groups were matched in terms of liver functional reserve and tumor location. LTP, IDR, and RFS showed little difference between the two therapies. However, MWA was able to significantly reduce the number of sessions required and ablation time. In addition to being therapeutically beneficial to the patient with less stress, this is also beneficial for the operator. New-generation MWA had been demonstrated to create a large predictable spherical ablation zone in clinical practice [22], and the benefits of spherical ablation may increase the accuracy of ablation strategies. Feng et al. adopted PSM and compared the treatment outcomes of MWA and RFA for perivascular HCC, and reported that RFS was significantly better in the MWA group than in the RFA group, although overall survival was similar [23]. However, the pursuit of local tumor progression after ablation, which is a major concern for perivascular HCC, had not been sufficient. Santambrogio et al. reported that MWA was associated with lower LTP in a retrospective study comparing the efficacy of laparoscopic MWA and RFA for 1-3 HCC tumors smaller than $3 \mathrm{~cm}$ in size [24]. However, there may have been a potential bias in the proportion of lesions adjacent/ non-adjacent to large vessels in the two treatment groups. In this study, the patient groups' baseline characteristics were matched, although differences in treatment devices were not identified as risk factors for LTP. Univariate analysis identified the vicinity of large vessels alone, while tumor diameter, combination therapy with TACE, ablation time, and the number of sessions did not pose a risk of local tumor progression. For risk factors associated with RFS, age, recurrent type, ALBI score, and tumor diameter were identified as independent risk factors by multivariate analysis. In this study, patients under the age of 65 years accounted for only $15 \%$ of the total study cohort, which may have led 
to an extraction bias. In other words, it may be the case that younger patients were more likely to choose curative surgery than older patients. Previous HCC therapies, the number of tumors, and the severity of the underlying liver disease were identified as risk factors in $\mathrm{HCC}$ recurrence, a finding which is supported by previous reports [25, 26].

Thermal ablation for HCC adjacent to large vessels causes portal vein thrombosis and severe bile duct injury, which can significantly decrease the patient's quality of life [27]. Given that the new-generation MWA system is less affected by the heat sink effect and allows for a large ablation zone, there were concerns about increased ablation complications for HCC, especially for tumors adjacent to large vessels. However, there was no difference between the two groups in terms of major complications in this study. This observation was similar to previous reports, including a large multicenter study in Italy and a systematic review comparing the complications of MWA and RFA [28, 29].

This study has some limitations. First, the RFA procedure was performed early in the study, while the MWA procedure was performed later, which may have resulted in bias. In addition, it was not possible to compare the long-term treatment outcomes due to the short follow-up period of MWA. Second, we utilized PSM to balance baseline characteristics, although selection bias may have occurred because of the retrospective study design. Third, since this is a singlecenter study, the generalizability of the results may be limited. However, this preliminary report on the performance of a new-generation MWA system lays the foundation for prospective research regarding the optimal PTA procedure for HCC.

\section{Conclusion}

The therapeutic effect of new-generation MWA was comparable to that of RFA, although MWA has advantages over RFA regarding efficacy, including shorter ablation time and fewer sessions required. Future research is required to accumulate more cases and compare long-term treatment outcomes.

\footnotetext{
Authors' contributions KS and TS designed the study and wrote the initial draft of the manuscript. NY contributed to the analysis and interpretation of data and assisted in the preparation of the manuscript. KA, MY, MM, AN, MS and MN contributed to data collection and interpretation and critically reviewed the manuscript. All authors approved the final version of the manuscript and agreed to be accountable for all aspects of the work in ensuring that questions related to the accuracy or integrity of any part of the work are appropriately investigated and resolved.
}

Funding No funding was received.
Data Availability The datasets used and/or analyzed during the present study are available from the corresponding author on reasonable request.

\section{Declarations}

Conflict of interest The authors declare that they have no competing interests.

Ethical approval The study protocol was conducted with the approval (approval no. 2018143) of the Ethics Committee of Kansai Medical University Medical Center (Moriguchi, Japan). All procedures performed in studies involving human participants were in accordance with the ethical standards of the Clinical Research Board of Kansai Medical University Medical Center and with the 1964 Helsinki Declaration and its later amendments or comparable ethical standards.

Informed consent Informed consent was obtained from all individual participants included in the present study. Further, we obtained patient consent for publication.

Open Access This article is licensed under a Creative Commons Attribution 4.0 International License, which permits use, sharing, adaptation, distribution and reproduction in any medium or format, as long as you give appropriate credit to the original author(s) and the source, provide a link to the Creative Commons licence, and indicate if changes were made. The images or other third party material in this article are included in the article's Creative Commons licence, unless indicated otherwise in a credit line to the material. If material is not included in the article's Creative Commons licence and your intended use is not permitted by statutory regulation or exceeds the permitted use, you will need to obtain permission directly from the copyright holder. To view a copy of this licence, visit http://creativecommons.org/licenses/by/4.0/.

\section{References}

1. Llovet JM, Burroughs A, Bruix J (2003) Hepatocellular carcinoma. Lancet 362 (9399):1907-1917. https://doi.org/10.1016/ S0140-6736(03)14964-1

2. Llovet JM, Bru C, Bruix J (1999) Prognosis of hepatocellular carcinoma: the BCLC staging classification. Semin Liver Dis 19 (3):329-338. https://doi.org/10.1055/s-2007-1007122

3. Bruix J, Sherman M, American Association for the Study of Liver D (2011) Management of hepatocellular carcinoma: an update. Hepatology 53 (3):1020-1022. https://doi.org/10.1002/hep.24199

4. Bruix J, Sherman M, Llovet JM, Beaugrand M, Lencioni R, Burroughs AK, Christensen E, Pagliaro L, Colombo M, Rodes J, HCC EPoEo (2001) Clinical management of hepatocellular carcinoma. Conclusions of the Barcelona-2000 EASL conference. European Association for the Study of the Liver. J Hepatol 35 (3):421-430. https://doi.org/10.1016/s0168-8278(01)00130-1

5. Gui CH, Baey S, D'Cruz R T, Shelat VG (2020) Trans-arterial chemoembolization + radiofrequency ablation versus surgical resection in hepatocellular carcinoma - A meta-analysis. Eur J Surg Oncol 46 (5):763-771. https://doi.org/10.1016/j. ejso.2020.01.004

6. Chen X, Chen Y, Li Q, Ma D, Shen B, Peng C (2015) Radiofrequency ablation versus surgical resection for intrahepatic hepatocellular carcinoma recurrence: a meta-analysis. J Surg Res 195 (1):166-174. https://doi.org/10.1016/j.jss.2015.01.042 
7. Chen MS, Li JQ, Zheng Y, Guo RP, Liang HH, Zhang YQ, Lin XJ, Lau WY (2006) A prospective randomized trial comparing percutaneous local ablative therapy and partial hepatectomy for small hepatocellular carcinoma. Ann Surg 243 (3):321-328. https ://doi.org/10.1097/01.sla.0000201480.65519.b8

8. Feng K, Yan J, Li X, Xia F, Ma K, Wang S, Bie P, Dong J (2012) A randomized controlled trial of radiofrequency ablation and surgical resection in the treatment of small hepatocellular carcinoma. J Hepatol 57 (4):794-802. https://doi.org/10.1016/j. jhep.2012.05.007

9. Fang Y, Chen W, Liang X, Li D, Lou H, Chen R, Wang K, Pan H (2014) Comparison of long-term effectiveness and complications of radiofrequency ablation with hepatectomy for small hepatocellular carcinoma. Journal of gastroenterology and hepatology 29 (1):193-200. https://doi.org/10.1111/jgh.12441

10. Alonzo M, Bos A, Bennett S, Ferral H (2015) The Emprint Ablation System with Thermosphere Technology: One of the Newer Next-Generation Microwave Ablation Technologies. Seminars in interventional radiology 32 (4):335-338. https://doi. org/10.1055/s-0035-1564811

11. Ierardi AM, Mangano A, Floridi C, Dionigi G, Biondi A, Duka E, Lucchina N, Lianos GD, Carrafiello G (2015) A new system of microwave ablation at $2450 \mathrm{MHz}$ : preliminary experience. Updates in surgery 67 (1):39-45. https://doi.org/10.1007/s1330 4-015-0288-1

12. Sacks D, McClenny TE, Cardella JF, Lewis CA (2003) Society of Interventional Radiology clinical practice guidelines. Journal of vascular and interventional radiology : JVIR 14 (9 Pt 2):S199-202. https://doi.org/10.1097/01.rvi.0000094584.83406.3e

13. Johnson PJ, Berhane S, Kagebayashi C, Satomura S, Teng M, Reeves HL, O'Beirne J, Fox R, Skowronska A, Palmer D, Yeo W, Mo F, Lai P, Inarrairaegui M, Chan SL, Sangro B, Miksad R, Tada T, Kumada T, Toyoda H (2015) Assessment of liver function in patients with hepatocellular carcinoma: a new evidence-based approach-the ALBI grade. J Clin Oncol 33 (6):550-558. https:// doi.org/10.1200/JCO.2014.57.9151

14. Kim HY, Nam JY, Lee JH, Lee HA, Chang Y, Lee HY, Cho H, Lee DH, Cho YY, Cho EJ, Yu SJ, Lee JM, Kim YJ, Yoon JH (2018) Intensity of surveillance for hepatocellular carcinoma determines survival in patients at risk in a hepatitis B-endemic area. Alimentary pharmacology \& therapeutics 47 (11):1490-1501. https://doi. org/10.1111/apt.14623

15. Lu DS, Raman SS, Limanond P, Aziz D, Economou J, Busuttil R, Sayre J (2003) Influence of large peritumoral vessels on outcome of radiofrequency ablation of liver tumors. Journal of vascular and interventional radiology : JVIR 14 (10):1267-1274

16. Lucchina N, Tsetis D, Ierardi AM, Giorlando F, Macchi E, Kehagias E, Duka E, Fontana F, Livraghi L, Carrafiello G (2016) Current role of microwave ablation in the treatment of small hepatocellular carcinomas. Annals of gastroenterology 29 (4):460-465. https://doi.org/10.20524/aog.2016.0066

17. Dou JP, Yu J, Yang XH, Cheng ZG, Han ZY, Liu FY, Yu XL, Liang P (2017) Outcomes of microwave ablation for hepatocellular carcinoma adjacent to large vessels: a propensity score analysis. Oncotarget 8 (17):28758-28768. https://doi.org/10.18632 /oncotarget.15672

18. Huang J, Yan L, Cheng Z, Wu H, Du L, Wang J, Xu Y, Zeng Y (2010) A randomized trial comparing radiofrequency ablation and surgical resection for HCC conforming to the Milan criteria. Ann Surg 252 (6):903-912. https://doi.org/10.1097/SLA.0b013e3181 efc656

19. Potretzke TA, Ziemlewicz TJ, Hinshaw JL, Lubner MG, Wells SA, Brace CL, Agarwal P, Lee FT, Jr. (2016) Microwave versus
Radiofrequency Ablation Treatment for Hepatocellular Carcinoma: A Comparison of Efficacy at a Single Center. Journal of vascular and interventional radiology : JVIR 27 (5):631-638. https ://doi.org/10.1016/j.jvir.2016.01.136

20. Abdelaziz A, Elbaz T, Shousha HI, Mahmoud S, Ibrahim M, Abdelmaksoud A, Nabeel M (2014) Efficacy and survival analysis of percutaneous radiofrequency versus microwave ablation for hepatocellular carcinoma: an Egyptian multidisciplinary clinic experience. Surgical endoscopy 28 (12):3429-3434. https://doi. org/10.1007/s00464-014-3617-4

21. Vogl TJ, Farshid P, Naguib NN, Zangos S, Bodelle B, Paul J, Mbalisike EC, Beeres M, Nour-Eldin NE (2015) Ablation therapy of hepatocellular carcinoma: a comparative study between radiofrequency and microwave ablation. Abdominal imaging 40 (6):1829-1837. https://doi.org/10.1007/s00261-015-0355-6

22. Suwa K, Seki T, Tsuda R, Yamashina M, Murata M, Yamaguchi T, Nishio A, Okazaki K (2020) Short term treatment results of local ablation with water-cooled microwave antenna for liver cancer: Comparison with radiofrequency ablation. Mol Clin Oncol 12 (3):230-236. https://doi.org/10.3892/mco.2020.1983

23. Feng Y, Wang L, Lv H, Shi T, Xu C, Zheng H, Qi J, Zhao X, Li J, Gao Y, Qin C, Zhu Q (2020) Microwave ablation versus radiofrequency ablation for perivascular hepatocellular carcinoma: a propensity score analysis. HPB (Oxford). https://doi.org/10.1016/j. hpb.2020.08.006

24. Santambrogio R, Chiang J, Barabino M, Meloni FM, Bertolini E, Melchiorre F, Opocher E (2017) Comparison of Laparoscopic Microwave to Radiofrequency Ablation of Small Hepatocellular Carcinoma $(</=3 \mathrm{~cm})$. Annals of surgical oncology 24 (1):257263. https://doi.org/10.1245/s10434-016-5527-2

25. Sparchez Z, Mocan T, Radu P, Mocan LP, Sparchez M, Leucuta DC, Al Hajjar N (2018) Prognostic Factors after Percutaneous Radiofrequency Ablation in the Treatment of Hepatocellular Carcinoma. Impact of Incomplete Ablation on Recurrence and Overall Survival Rates. J Gastrointestin Liver Dis 27 (4):399-407. https://doi.org/10.15403/jgld.2014.1121.274.pro

26. Nouso K, Matsumoto E, Kobayashi Y, Nakamura S, Tanaka H, Osawa T, Ikeda H, Araki Y, Sakaguchi K, Shiratori Y (2008) Risk factors for local and distant recurrence of hepatocellular carcinomas after local ablation therapies. Journal of gastroenterology and hepatology 23 (3):453-458. https://doi.org/10.111 $1 / \mathrm{j} .1440-1746.2007 .05120 . x$

27. Rhim H (2005) Complications of radiofrequency ablation in hepatocellular carcinoma. Abdominal imaging 30 (4):409-418. https:// doi.org/10.1007/s00261-004-0255-7

28. Bertot LC, Sato M, Tateishi R, Yoshida H, Koike K (2011) Mortality and complication rates of percutaneous ablative techniques for the treatment of liver tumors: a systematic review. Eur Radiol 21 (12):2584-2596. https://doi.org/10.1007/s00330-011-2222-3

29. Livraghi T, Meloni F, Solbiati L, Zanus G, Collaborative Italian Group using As (2012) Complications of microwave ablation for liver tumors: results of a multicenter study. Cardiovasc Intervent Radiol 35 (4):868-874. https://doi.org/10.1007/s0027 0-011-0241-8

Publisher's Note Springer Nature remains neutral with regard to jurisdictional claims in published maps and institutional affiliations. 